\title{
PREVALENCE OF PERIODONTAL DISEASES IN CHILDREN WITH DOWN SYNDROME
}

\author{
Radosveta Andreeva, Siyana Atanasova \\ Department of Pediatric dentistry, Faculty of Dental Medicine, Medical \\ University Varna Bulgaria.
}

\begin{abstract}
Down syndrome - trisomy of 21 chromosome is the most common chromosome anomaly, which affects children worldwide. The aim of this study is to compare the distribution of periodontal disease among Down syndrome children and healthy children. 60 children and adolescents with Down syndrome and 60 healthy children were examined in the same age group. Plaque index (PI) (Silness\&Loe), probing depth (PD) were registered. The plaque index of children with Down syndrome under 6 years is 0.81 . For the children between $6-11$ years, this index is 1.4 and for the third group it is 1,8. For the healthy children the values of the PI are: under 6 years -0.9 ; between $6-11-1.2$; between 11-15 - 2.2. The measured pocket depths of the children with DS for the three examined are as follows: under 6 years - 3.5; between 6-11 - 4.1; between 11-15 - 4.7. For the healthy children the values of the PPD are: under 6 years 2.6; between 6-11 - 3.3; between 11-15 - 3.0. Conclusion: There are more frequent periodontal problems for Down syndrome children, which does not correspond with the level of their oral hygiene.
\end{abstract} children,

Keywords: periodontal disease, Down syndrome,

\section{INTRODUCTION}

Down syndrome - a trisomy of 21 is the most common chromosome anomaly, which is observed in newborns worldwide. [1, 2, 3] The frequency of DS is higher in proportion to the age of the mother. Depending on the age of the mother the frequency is $1: 500$ up to $1: 800$. [4, 5] Down syndrome is characterized with certain physical anomalies - under average height, small and round flat face with oblique, mongoloid eyes, small nose and ears, a large, fissured tongue, that is often hanging from the mouth, bifurcated uvula, a short neck, polydactyl, syndactyl or clinodactyl fingers. The clinical aspects of this syndrome are predisposition to congenital heart deformities, myeloid leukemia, celiac disease, thyroid diseases, frequent infections of the upper respiratory tracts, etc. $[4,5,6,7,8]$. The problems related to the oral and dental health remain neglected. A lot of the medical and physiological characteristics of Down syndrome have direct impact and consequences on the oral health of the patients. The oral and dental diseases have a higher frequency in special needs children. Down syndrome children often develop gingivitis and fast-progressing and generalized periodontitis in early age. $[9,10]$

\section{AIM}

The aim of this study is to do a comparison of the prevalence of periodontal disease in Down syndrome children and healthy children.

\section{MATERIALS AND METHODS}

60 children and adolescence with Down syndrome and 60 healthy children between 3-15 years old were examined (under 6 years, 6-11 years, 11-15 years) with primary, mixed or permanent dentition. None of the participants in both groups have any medical conditions that may effect the condition of the periodontium, neither do they intake medications, which would affect the periodontal status. Plaque index (PI) (Silness\&Loe) and probing depth (PD) were registåred. Silness and Loe index is based on recording both soft debris and mineralized deposits on the following teeth. A probe with atraumatic tip was used on the four surfaces, without the occlusal one. For every patient the dentition is divided into 6 sextants - upper left, upper front, upper right, lower right, lower front and lower left respectively. The representative teeth are- 16, $11,26,36,31,46$. In the primary dentition representatives are $55,51,65,75,71,85$. Each of the surfaces of the teeth is given a score from $0-3$. The scores from the four areas of the tooth are added and divided by 4 , in order to give the plaque index for the tooth with the following scores and criteria:

0 - No plaque

1- A film of plaque, adhering to the free gingival margin and adjacent area of the tooth. The plaque could be seen by using the probe on the tooth surface

2 - moderate accumulation of soft deposits within the gingival pocket, or the tooth and gingival margin, which can be seen with the naked eye

3 - abundance of soft matter within the gingival pocket and/or the tooth and gingival margin

Interpretation of PI

0 - Excellent oral hygiene

$0.1-0.9$ - Good oral hygiene

$1.0-1.9$ - Fair oral hygiene

$2.0-3.0$ - Poor oral hygiene 
The PPD is measured by inserting a periodontal probe into the gingival sulcus. The distance from the free gingival margin to the depth of the sulcus or pocket is the periodontal probing depth. It should be measured and recorded at several sites around the circumference of each tooth. Pockets deeper that $4 \mathrm{~mm}$ may indicate periodontitis.

The results are statistically processed with SPSS v

Tabl. 1. Plaque index for Down syndrome children
20.0, with the use of ANOVA and t-test. Level of significance $(\mathrm{p}<0.05)$.

\section{RESULTS}

The plaque index of children with Down syndrome under 6 years is 1.81. For the children between $6-11$ years, this index is 2.4 and for the third group it is 2,8 (Tabl. 1).

\begin{tabular}{|l|c|c|c|c|}
\hline PLI & Groups & 6-12 years & $>12$ years & P-value \\
\cline { 1 - 3 } Mean & 1.81 & 2.4 & 2.8 & $\mathbf{P = 0 . 0 2}$ \\
\cline { 1 - 3 } & 0.73 & 0.79 & 0.70 & \\
\hline
\end{tabular}

There is a statistically significant difference between the three investigated groups of Down syndrome children. The plaque index of the healthy children (control group) under 6 years is 0.9 . For the children between $6-11$ years, this index is 1.2 and for the third group it is 2.2 (Tabl. 2). There is a statistically significant difference between the three investigated groups of the heathy children.

Tabl. 2. Plaque index for healthy children

\begin{tabular}{|l|c|c|c|c|}
\hline PLI & $<6$ years & 6-12 years & $>12$ years & P-value \\
\hline Mean & 0.9 & 1.2 & 2.2 & P< 0.05 \\
\cline { 1 - 3 } & 0.24 & 0.69 & 0.71 & \\
\hline
\end{tabular}

Comparing the results of the plaque index of the DS children and the healthy children it's obvious that the results for the group of the youngest children under 6 years that these indices differ substantially: 1.81 for DS children and 0.9 for the control group. For the second age group 611 years these indices also differ: 2.4 for DS and 1.2 for the healthy children. In the third age group the values of the plaque index for the healthy and the DS children are similar: 2.8 for DS and 2.2 for healthy children. The measured pocket depths of the children with DS for the three examined are as follows: under 6 years -3.5 ; between 6-11 4.1; between 11-15 - 4.7 (Tabl. 3 ).

Tabl. 3. Periodontal pocket depth for Down syndrome children

\begin{tabular}{|l|c|c|c|c|}
\hline PPD & $<6$ years & $6-12$ years & $>12$ years & P-value \\
\cline { 1 - 3 } Mean & 3,5 & 4,1 & 4,7 & P= 0.04 \\
\cline { 1 - 3 } & 0.45 & 1.16 & 1.02 & \\
\hline
\end{tabular}

For the healthy children the values of the PPD are: under 6 years - 2.6; between 6-11 - 3.3; between 11-153.0 (Tabl. 4).

Tabl. 4. Periodontal pocket depth for healthy children

\begin{tabular}{|l|c|c|c|c|}
\hline PPD & $<6$ years & $6-12$ years & $>12$ years & P-value \\
\cline { 1 - 3 } Mean & 2.6 & 3.3 & 3.0 & P>0.05 \\
\cline { 1 - 3 } & 0.74 & 1.08 & 0.98 & \\
\hline
\end{tabular}




\section{DISCUSSION}

The Down syndrome patients have a significantly higher prevalence of periodontal diseases, compared to their healthy peers. [7, 11, 12]. Subsequently, many investigations revealed that children and adolescents with Down syndrome often develop extensive gingivitis, and exhibit rapid and generalized periodontal breakdown in early adulthood. [19] Individuals with Down syndrome have an increased prevalence of periodontal disease as compared with normal of similar age distribution $[\underline{9}, \underline{10}, 13,14,15]$

Our results show that DS and healthy children from the three examined groups have poor oral hygiene, which is similar to the healthy children. Our results show that with increase in age the plaque index increases in direct ratio in the three groups of healthy and DS children, and the DS children have poorer oral hygiene than their healthy peers. The following results correspond to the ones, registered from other authors. $[16,17]$ The results concerning pocket depth increase with age for both groups, except for the second age group of healthy children, who have a higher PPD index, compared to the first group. Down syndrome children have higher PPD index, compared to healthy children in all age groups. This is based on the fact, that in mixed dentition due to the eruption of the permanent teeth, it is normal to have deeper periodontal pockets, which do not exceed $4 \mathrm{~mm}$. [18] Our results are similar with other published authors. The number of deep periodontal pockets is higher in Down syndrome children, compared to healthy children. [19, 20, 21] Dow uses the term "parodontoclasia" to explain the periodontal changes that occur in Down syndrome children. According to him local factors don't have as much significance in determining the clinical picture, as anoxia does. [22] Even in Down syndrome children, such a poor oral hygiene reportedly gave rise to earlier, more rapid, and more extensive gingival inflammation in deciduous dentition, as compared to normal control children [13, 23]. However, this situation seems to be steadily improved by better dental care for these individuals, both at home and the dental office, as compared with the past. Indeed, some recent reports showed that better oral hygiene existed in Down syndrome children [17], or there was no significant difference as compared to healthy children [24, 25]. Collectively, individuals with Down syndrome likely respond to common bacterial challenges in an exaggerated manner, due to multiple factors, and develop more severe forms of periodontal disease. There is a higher incidence of oral health problems among individuals with Down syndrome, particularly after 10 years of age $[20,21]$ indicating the need for better teaching of tooth brushing and more regular visits to the dentist. Conventional standard procedures of oral hygiene instruction, scaling, and root planing, as well as surgical therapy lead to significant improvements in Down syndrome patients $[17,26]$.

\section{CONCLUSION}

In children with Down syndrome there is a higher predisposition for periodontal diseases, which rarely occurs in healthy children. The plaque index and pocket depth for children with Down syndrome are higher than that of the control group, which acts as a risk factor for the development of periodontal problems. No matter that dental plaque and pocket depth may have a significant role in the etiology of periodontal disease, other etiological factors could be found in DS children.

\section{REFERENCES:}

1. Mussing D, Hickel R, Zschiesche S. [The eruption of deciduous teeth in children with various forms of Down's syndrome and congenital heart defects.] [in German] Dtsch Zahnarztl Z. 1990 Mar;45(3): 157-9. [PubMed]

2. Facts about Down syndrome. NADS. November 2018. [Internet]

3. Down Syndrome for Kids. Reviewed by: Gavin ML. September 2015. KidsHealth.org [Internet]

4. Shapkova-Taneva P. [Development of fine motor skills and self-care skills in children with Down syndrome.] Special pedagogy. 2007; 3(1):4955. [in Bulgarian].

5. Shapkova-Taneva P. [Down syndrome myths and realities.] Special pedagogy. 2009; 1(1): 30-9. [in Bulgarian]

6. Sznajder N, Carraro JJ, Otero E,
Carranza Jr. FA. Clinical periodontal findings in trisomy 21 (mongolism). J Periodontal Res. 1968; 3(1):1-5. [PubMed]

7. Asokan S, Muthu M, Sivakumar N. Oral findings of Down's syndrome children in Chennai city, India. Indian J Dent Res. 2008; 19(3):230-35.

8. Christensen GJ. Special oral hygiene and preventive care for special needs. J Am Dent Assoc. 2005 Aug; 136(8):1141-3. [PubMed] [Crossref]

9. Ziåtek Ì, Kaczmarek U. Oral hygiene and periodontal status in children and adolescents with Down syndrome. Nowa Stomatol. 2019; 24(1):20-2. [Internet]

10. Orner G. Periodontal disease among children with Down's syndrome and their siblings. J Dent Res. 1976 Sep-Oct;55(5):778-82. [PubMed] [Crossref]
11. Ferreira R, Michel RC, Greghi SLA, de Resende MLR, Passanezi Sant'Ana AC, Damante CA, et al. Prevention and Periodontal Treatment in Down Syndrome Patients: A Systematic Review. PLoS One. 2016 Jun 29; 11(6):e0158339. [PubMed] [Crossref]

12. Backman B, Grever-Sjolander A-C, Bengtsson K, Persson J, Johansson I. Children with Down syndrome: oral development and morphology after use of palatal plates between 6 and 48 months of age. Int J Paediatr Dent. 2007 Jan;17(1):19-28. [PubMed] [Crossref]

13. Rahul VK, Mathew C, Jose S, Thomas G, Noushad MC, Mohammed Feroz TP. Oral manifestation in mentally challenged children. J Int Oral Health. 2015 Feb;7(2):37-41. [PubMed]

14. Singh S, Vandana KL. Assess- 
ment of width of attached gingiva in primary, mixed, and permanent dentition: Part - 2. SRM J Res Dent Sci. 2017; 8:157-61. [Crossref]

15. Rashkova M. [Periodontal diseases in children and adolescents] [Monograph]. Direct Services, Sofia. 2016. [in Bulgarian]

16. Roba I, Elena ZS, de los Angeles DM, Gustavo S. Prevalence of Periodontal Disease in Young Adults with Down Syndrome. J Oral Health Dent Sci. 2018; 2(3):7 pages. [Internet]

17. Cheng RHW, Leung WK, Corbet EF, King NM. Oral health status of adults with Down syndrome in Hong Kong. Spec Care Dentist. 2007 Jul-Aug;27(4):134-8 . [PubMed] [Crossref]

18. Rashkova M, Mitova N, Tankova H. Gingival sulcus depth in various tooth groups during eruption. $J$ of IMAB. 2018 Jul-Sep;24(3):21002103. [Crossref]
19. Bagic I, Verzak Z, CukovicCavka S, Brkic H, Susic M. Periodontal conditions in individuals with Down's syndrome. Coll Antropol. 2003;27 Suppl 2:75-82. [PubMed]

20. Yoshihara T, Morinushi T, Kinjyo S, Yamasaki Y. Effect of periodic preventive care on the progression of periodontal disease in young adults with Down's syndrome. J Clin Periodontol. 2005 Jun;32(6):556-60. [PubMed] [Crossref]

21. Shekar S, Bhagyalakshmi A, Chandrashekar BR, Avinash BS. Periodontal considerations during orthodontic treatment. Indian J Oral Health Res. 2017; 3(1):1-8. [Crossref]

22. Gupta P, Hegde A. Pediatric dentistry for special child. First edition. JAYPEE. March 2016. pp.269273. [Internet]

23. Sterling ES. Oral dental considerations in Down syndrome. In: Down Syndrome: Advances in Medical Care. Lott IT, McCoy EE. Eds.
Wiley-Liss, New York. 1992. pp. 135145. [Internet]

24. Morinushi T, Lopatin DE, Nakao R, Kinjyo S. A comparison of the gingival health of children with Down syndrome to healthy children residing in an institution. Spec Care Dentist.2006 Jan-Feb;26(1):13-9. [PubMed] [Crossref]

25. Cogulu D, Sabah E, Kutukculer N, Ozkinay F. Evaluation of the relationship between caries indices and salivary secretory IgA, salivary $\mathrm{pH}$, buffering capacity and flow rate in children with Down's syndrome. Arch Oral Biol. 2006 Jan; 51(1):23-8. [PubMed] [Crossref]

26. Zaldivar-Chiapa RM, ArceMendoza AY, De La Rosa-Ramirez M, Caffesse RG, Solis-Soto JM. Evaluation of surgical and non-surgical periodontal therapies, and immunological status, of young Down's syndrome patients. JPeriodontol. $2005 \mathrm{Jul}$; 76(7):1061-5. [PubMed] [Crossref]

Please cite this article as: Andreeva R, Atanasova S. Prevalence of periodontal diseases in children with Down syndrome. J of IMAB. 2020 Oct-Dec;26(4):3383-3386. DOI: https://doi.org/10.5272/jimab.2020264.3383

Received: 17/03/2020; Published online: 20/10/2020

\section{Address for correspondence:}

Assoc. Prof. Radosveta Andreeva-Borisova, PhD, DsC

Department of Pediatric Dental Medicine, Faculty Dental Medicine, Medical University Varna

Bul. Tsar Osvoboditel 84, Varna, Bulgaria

E-mail: doctor_ra@abv.bg, 